\title{
The relationship between joint hypermobility and subacromial impingement syndrome and adhesive capsulitis of the shoulder
}

\author{
Arzu Atici, Ilknur Aktas, Pinar Akpinar, Feyza Unlu Ozkan \\ ${ }^{1}$ Department of Physical Medicine and Rehabilitation, University of Health Sciences, Fatih Sultan Mehmet \\ Training and Research Hospital, Istanbul, Turkey
}

\begin{abstract}
OBJECTIVE: Joint hypermobility $(\mathrm{JH})$ is a clinical condition in which the joints move beyond the expected physiological range of motion. $\mathrm{JH}$ can be accompanied by many musculoskeletal complaints. One of the common causes of musculoskeletal pain is shoulder pain. The aim of this study was to investigate the relationship between subacromial impingement syndrome (SAIS), shoulder adhesive capsulitis (AC), and JH in patients with shoulder pain.

METHODS: Patients aged between 18 and 70 years who presented at the physical medicine and rehabilitation outpatient clinic and who were diagnosed with SAIS or AC in a clinical and physical examination were included in the study. Patients in the same age group without musculoskeletal system pain were included in a control group. All of the cases were assessed for hypermobility using the Beighton score for generalized joint hypermobility $(\mathrm{GJH})$, and the revised 1998 Brighton criteria for benign joint hypermobility syndrome (BJHS).

RESULTS: Of the 124 cases included in the study, 71 (57.3\%) were female and $53(42.7 \%)$ were male. There was no case of $\mathrm{GJH}$ in the AC group. There were $2(4.50 \%)$ cases in the SAIS group and $3(7.5 \%)$ in the control group. BJHS was found in 4 $(10 \%)$ cases in the AC group, $6(13.63 \%)$ in the SAIS group, and 2 (5\%) cases in the control group. There was no statistically significant difference between groups in terms of $\mathrm{JH}(p>0.05)$. The Beighton scores of the AC group were statistically lower those of the control group $(p<0.05)$.

CONCLUSION: The results of this study indicated no significant difference between the SAIS group, the AC group, and the control group in terms of GJH and BJHS. The fact that Beighton scores were lower in the AC group than in the control group suggests that the probability of developing $\mathrm{AC}$ in those with $\mathrm{JH}$ may be lower.
\end{abstract}

Keywords: Adhesive capsulitis of the shoulder; joint hypermobility; subacromial impingement syndrome.

Cite this article as: Atici A, Aktas I, Akpinar P, Unlu Ozkan F. The relationship between joint hypermobility and subacromial impingement syndrome and adhesive capsulitis of the shoulder. North Clin Istanb 2018;5(3):232-237.

Tointeri oint hypermobility $(\mathrm{JH})$ is a clinical condition characterized an excess range of motion in a joint beyond the physiological range of motion [1]. When the condition is asymptomatic, it is termed generalized joint hypermobility $(\mathrm{GJH})$; however, when it is associated with symptoms such as arthralgia, soft tissue damage, and joint instability, it is referred to as benign joint hypermobility syndrome
(BJHS) [2]. JH is more common in young people; the incidence decreases with age. The incidence in the general population has been reported to range between $10 \%$ and $20 \%$ [3]. An increase in the proportion of collagen or collagen subtypes, such as type III/type I has been detected in $\mathrm{JH}[4,5]$. This abnormal collagen structure causes joint laxity, and fragility of the connective tissue increases. This

Received: July 24, 2017 Accepted: October 17, 2017 Online: April 16, 2018

Correspondence: Dr. Arzu ATICI. Saglik Bilimleri Universitesi Fatih Sultan Mehmet Egitim ve Arastirma Hastanesi, Fiziksel Tip ve Rehabilitasyon Anabilim Dali, Istanbul, Turkey.

Phone: +90 21657830 00-3745 e-mail: drsusin@mynet.com

(c) Copyright 2018 by Istanbul Provincial Directorate of Health - Available online at www.northclinist.com 
condition predisposes the individual to musculoskeletal pathologies.

Shoulder pain is one of the widely seen causes of musculoskeletal system pain, and affects some $7 \%$ to $34 \%$ of the population [6]. Subacromial impingement syndrome (SAIS) and adhesive capsulitis (AC) of the shoulder are the most common causes of shoulder pain. SAIS occurs as a result of impingement of soft tissues, especially the supraspinatus muscle, the subacromial bursa, and the biceps tendon between the humerus and the coracoacromial arch [7]. SAIS may develop secondary to structural or functional etiologies [8]. In the literature, it has been suggested that $\mathrm{JH}$ may contribute to clinical manifestations of SAIS [9]. AC is a disease characterized by shoulder pain and a restricted range of joint motion which affects a reported $2 \%$ to $5 \%$ of the population [10]. AC may manifest without any etiology, or it may develop secondary to a local problem (shoulder rotator cuff rupture, calcific tendonitis, trauma) or systemic disease (diabetes mellitus, hypo- or hyperthyroidism) $[11,12]$. The basic event in its pathogenesis is the development of fibrosis in the joint capsule as a result of an accumulation of fibroblasts and myofibroblasts in type I and type III collagen tissue $[13,14]$. As a result, the range of motion of the joint is both actively and passively restricted.

Both SAIS and AC cause pain and disability. In this study, the aim was to investigate the association of SAIS and $\mathrm{AC}$, which are etiological agents of joint pain with different pathophysiological mechanisms, with $\mathrm{JH}$.

\section{MATERIALS AND METHODS}

A total of 124 patients aged between 18 and 70 years who presented at the outpatient clinic of physical medicine and rehabilitation with complaints of shoulder pain and who were diagnosed with SAIS or AC based on their medical history and a clinical examination, and agematched healthy control subjects without any musculoskeletal complaints were enrolled in the study. Before the research was initiated, the participants were informed about the study design, and written informed consent was obtained. The subacromial injection test (SET) was administered to cases with positive Hawkins-Kennedy test, Neer test, and painful arc test results. SET-positive patients were included in the SAIS group. SET was performed using an anterior approach after injecting $5 \mathrm{cc} 1 \%$ lidocaine solution with a $21-\mathrm{G}$ needle tip inserted just below the acromion and advanced into the subacromial space. The SET test was considered positive if the pa-
TABLE 1. Beighton hypermobility score

\begin{tabular}{|c|c|c|}
\hline & Right & Left \\
\hline Dorsiflexion of the fifth metocarpal joint $\left(>90^{\circ}\right)$ & 1 & 1 \\
\hline $\begin{array}{l}\text { Passive apposition of the thumb to the flexor } \\
\text { aspect of the forearm }\end{array}$ & 1 & 1 \\
\hline Passive hyperextension of the elbow $\left(>10^{\circ}\right)$ & 1 & 1 \\
\hline Passive hyperextension of the knee $\left(>10^{\circ}\right)$ & 1 & 1 \\
\hline $\begin{array}{l}\text { Palms of the hands resting flat on the floor with the } \\
\text { patient standing erect with fully extended knees }\end{array}$ & 1 & \\
\hline Total & 9 & \\
\hline
\end{tabular}

tient's pain was relieved and active and/or passive range of motion of the affected shoulder improved $80 \%[15,16]$. For the diagnosis of AC, the diagnostic criteria defined by Bulgen et al. [17] were used: shoulder pain persisting for at least 1 month, nighttime pain or the inability to lie on the affected side, restriction of active and passive range of motion of the shoulder joint in all directions, and at least $50 \%$ restriction of external rotation in the affected shoulder compared with the normal contralateral shoulder $[17$, 18]. Patients with a history of inflammatory disease, malignancy, shoulder trauma within the previous 6 months, shoulder surgery, or a plain radiogram that revealed the presence of osteoarthritis or calcification of the shoulder joint were not included in the study. Demographic data of all of the study participants were recorded. The duration of the shoulder pain and characteristics of the shoulder pain (activity pain, nighttime pain) of the cases diagnosed as AC and SAIS were noted. The Beighton hypermobility scoring system was used to evaluate $\mathrm{GJH}$, and a score of $\geq 4$ points was accepted as indicative of GJH (Table 1). BJHS was evaluated based on the revised 1998 Brighton criteria (Table 2) $[19,20]$.

The ethics committee of Istanbul Fatih Sultan Mehmet Training and Research Hospital approved of this study.

\section{Statistical analyses}

IBM SPSS Statistics for Windows, Version 22.0 (IBM Corp., Armonk, NY, USA) was used for the statistical analysis of the study data. Normal distribution was evaluated using the Shapiro-Wilk test. Descriptive statistics of mean, SD, and frequencies were calculated. A one-way analysis of variance was used for intergroup comparisons of quantitative data with a normal distribution pattern. For intergroup comparisons of parameters with non-normal distribution, the Kruskal-Wallis and Mann-Whitney 


\section{TABLE 2. Revised 1998 Brighton criteria}

Major criteria:

Beighton score of $4 / 9$ or greater (either currently or historically)

Arthralgia for longer than 3 months in 4 or more joints

Minor criteria:

Beighton score of 1,2 , or $3 / 9$ ( $0,1,2$,or $3 / 9$ if aged $>50$ years)

Arthralgia in one to three joints or back pain for more than 3 months, spondylolysis, spondylolysis/spondylolisthesis

Dislocation/subluxation in more than one joint or in one joint on more than one occasion

Soft tissue rheumatism with $>3$ lesions (e.g., bursitis, tenosynovitis, epicondylitis)

Marfanoid habitus (tall, slim, span/height ratio $>1.03$, upper/lower segment ratio $<0.89$, arachnodactyly (positive Steinberg/wrist

signs)

Cutaneous lesions: striae, hyperextensibility, thin skin

Eye signs: Drooping eyelids, myopia, or antimongoloid slant

Varicose veins or hernia or uterine/rectal prolapse

Required diagnostic criteria:

2 major criteria

1 major and 2 minor criteria

4 minor criteria

Presence of BJHS in first degree relatives and 2 minor criteria

*diagnosis of joint hypermobility syndrome is ruled out in the presence of collagen tissue diseases, such as Marfan syndrome and

Ehler-Danlos syndrome.

*Criteria Major 1 and Minor 1 are mutually exclusive, as are Major 2 and Minor 2.

$\mathrm{U}$ tests were used. A chi-square test and the Fisher-Freeman-Halton exact test were applied to compare qualitative data. Statistical significance was evaluated at $\mathrm{p}<0.05$.

\section{RESULTS}

A total of 124 (female: $n=71,57.3 \%$; male: $n=53,42.7 \%$ ) participants were included in the study. The mean age was $54.69 \pm 9.07$ years (range: $29-70$ years). The cases were divided into AC $(n=40)$, SAIS $(n=44)$, and healthy control $(n=40)$ groups.

No statistically significant intergroup difference was found with regard to mean age, gender, or hand dominance $(p>0.05)$. (Table 3$)$ In addition, no statistically significant intergroup difference was detected between the AC and SAIS groups with respect to duration of the

TABLE 3. Demographic and clinical characteristics of the groups

\begin{tabular}{|c|c|c|c|c|}
\hline & AC group & SAIS group & Control group & $\mathrm{p}$ \\
\hline Age (years; mean $\pm S D$ ) & $57.55 \pm 7.65$ & $53.57 \pm 10.54$ & $53.08 \pm 8.14$ & 0.051 \\
\hline \multicolumn{5}{|l|}{ Gender } \\
\hline Female & $18(45 \%)$ & $27(61.36 \%)$ & $26(65 \%)$ & 0.154 \\
\hline Male & $22(55 \%)$ & $17(38.63 \%)$ & $14(35 \%)$ & \\
\hline \multicolumn{5}{|l|}{ Dominant hand } \\
\hline Right & $38(95 \%)$ & $43(97.72 \%)$ & 37 (92.5\%) & 0.519 \\
\hline Left & $2(5 \%)$ & $1(2.27 \%)$ & $3(7.5 \%)$ & \\
\hline
\end{tabular}

AC: Adhesive capsulitis; SAIS: Subacromial impingement syndrome 


\begin{tabular}{|c|c|c|c|}
\hline & AC group & SAIS group & $\mathrm{p}$ \\
\hline \multicolumn{4}{|l|}{ Region, $\mathrm{n}(\%)$} \\
\hline Right shoulder & $20(50 \%)$ & $22(50 \%)$ & \\
\hline Left shoulder & $19(47.50 \%)$ & $19(43.18 \%)$ & 0.635 \\
\hline Both shoulders & $1(2.50 \%)$ & $3(6.81 \%)$ & \\
\hline Duration of pain (months; mean \pm SD) & $7.58 \pm 8.5(5.5)$ & $14.73 \pm 27.03(4)$ & 0.715 \\
\hline \multicolumn{4}{|l|}{ Shoulder pain, n (\%) } \\
\hline Nighttime pain & $5(12.50 \%)$ & $9(20.45 \%)$ & 0.620 \\
\hline Activity pain & $3(7.50 \%)$ & $3(6.81 \%)$ & \\
\hline Both nighttime and activity pain & $32(80 \%)$ & $32(72.72 \%)$ & \\
\hline
\end{tabular}

AC: Adhesive capsulitis; SAIS: Subacromial impingement syndrome

TABLE 5. Comparison of Beighton score, GJH, and BJHS between groups

\begin{tabular}{lcccc} 
& AC group & SAIS group & Control group & $\mathrm{p}$ \\
\hline $\begin{array}{l}\text { Beighton score (mean } \pm \text { SD) } \\
\text { GJH n (\%) }\end{array}$ & $0.28 \pm 0.64$ & $0.68 \pm 1.18$ & $0.93 \pm 1.27(0)$ & $0.045 *$ \\
$\quad$ Present & $0(0 \%)$ & $2(4.5 \%)$ & $3(7.5 \%)$ & 0.279 \\
Absent & $40(100 \%)$ & $42(95.5 \%)$ & $37(92.5 \%)$ & \\
BJHS n (\%) & $4(10 \%)$ & $6(13.6 \%)$ & $2(5 \%)$ & 0.482 \\
$\quad \begin{array}{l}\text { Present } \\
\text { Absent }\end{array}$ & $36(90 \%)$ & $38(86.4 \%)$ & $38(95 \%)$ & \\
\hline
\end{tabular}

$* \mathrm{p}<0.05$

AC: Adhesive capsulitis; BJHS: Benign joint hypermobility syndrome; GJH: Generalized joint hypermobility; SAIS: Subacromial impingement syndrome

shoulder pain, or the occurrence of nighttime and activity pain ( $p>0.05)$ (Table 4$)$.

In the entire study group, $5(4.03 \%)$ cases of GJH were observed and $12(9.68 \%)$ cases of BJHS. GJH was seen in $2(4.50 \%)$ SAIS patients and in $3(7.5 \%)$ controls; no cases of GJH were detected in the AC group. BHJS was present in 4 (10\%) patients in the AC group, 6 (13.63\%) of the SAIS group, and $2(5 \%)$ of the controls. No statistically significant intergroup difference was found between the GJH and BJHS groups ( $p>0.05)$. However, the Beighton hypermobility scores of the AC patients were statistically significantly lower than those of the control group $(\mathrm{p}<0.05)$ (Table 5).

\section{DISCUSSION}

We investigated the association between SAIS and AC, the most frequently encountered shoulder diseases in our clinical practice, and JH. No relationship with JH was observed in the 2 patient groups or the control group; however, the Beighton hypermobility score was significantly lower in the AC group compared with the control group.

As an asymptomatic condition, GJH may confer advantages in activities as dance and gymnastics [21]. When it becomes symptomatic, it is called BJHS and may include musculoskeletal problems. Aktas et al. [22] detected a positive correlation between carpal tunnel syndrome and BJHS. In another study, BJHS was described as a potential risk factor for lumbar disc herniation [23]. Higher rates of $\mathrm{JH}$ have been reported in fibromyalgia patients relative to a control group [24, 25]. Gürer et al. [26] asserted that GJH may increase the risk of knee osteoarthritis. Joint injuries related to hypermobility are often seen. In a study performed with professional football players, the incidence of injuries to the lower extremities, 
and particularly femur and ankle traumas, was greater in individuals with GJH [27]. GJH increases the risk of musculoskeletal system injuries and adversely affects the recovery period and the quality of healing due to the impaired collagen structure [20].

The shoulder is one of the joints most often affected by hypermobility. In a study conducted by Tobias et al. [28], the authors reported that in cases of GJH in adolescents, it was most frequently accompanied by shoulder, knee, or ankle pain. In another study, it was reported that the incidence of generalized body pain was higher in a group of patients diagnosed with BJHS and Hypermobile Type Ehler-Danlos Syndrome when compared with a healthy control group. The patients also frequently experienced neck pain, followed by shoulder pain. The Western Ontario Instability Index (WOSI) scores used to evaluate shoulder function in these patients were lower than those recorded in the control group [29].

The risk of joint instability increases in cases with $\mathrm{JH}$. Although subluxations are not a specific characteristic of BJHS, recurrent subluxations indicate the severity of laxity and local muscular weakness [21]. Cameron et al. [30] detected a correlation between GJH and glenohumeral joint instability independent of gender or race and suggested the use of $\mathrm{GJH}$ scoring as a risk factor for joint instability.

Similarly to our study, Terzi et al. [31] investigated the impact of $\mathrm{GJH}$ on the etiopathogenesis of $\mathrm{AC}$, and compared cases with AC and SAIS with respect to JH. They detected lower rates of GJH and BJHS in the AC group, and suggested that $\mathrm{GJH}$ might be a protective factor against the development of $\mathrm{AC}$ in cases with joint pain.

In our study we did not find any statistically significant difference between cases with SAIS and AC in terms of GJH. The Beighton hypermobility scores in the SAIS group were not significantly different from those of the control group, but were lower in the AC group. This finding suggests a potentially lower risk of developing $\mathrm{AC}$ in cases with $\mathrm{JH}$. However, this subject requires additional studies performed with a larger number of cases. The incidence of JH decreases with age. Since the median age of our study population was 54 years, we might have observed a smaller percentage of $\mathrm{GJH}$ in our study participants. Monitoring young individuals with $\mathrm{JH}$ may enable a healthier solution for shoulder complaints in later years.

In conclusion, we did not detect any difference in GJH and BJHS between the SAIS and AC groups. The lower Beighton hypermobility scores in the AC group relative to the control group suggest that there may be a lower risk of $\mathrm{AC}$ in cases with $\mathrm{JH}$.

Conflict of Interest: No conflict of interest was declared by the authors.

Financial Disclosure: The authors declared that this study has received no financial support.

Authorship Contributions: Concept - A.A., I.A.; Design - I.A., P.A.; Supervision - A.A., F.U.O.; Materials - A.A., P.A.; Data collection \&/or processing - P.A., F.U.O.; Analysis and/or interpretation - A.A., P.A.; Writing - A.A, P.A; Critical review - I.A., F.U.O.

\section{REFERENCES}

1. Simmonds JV, Keer RJ. Hypermobility and the hypermobility syndrome. Man Ther 2007;12:298-309. [CrossRef]

2. Ross J, Grahame R. Joint hypermobility syndrome. BMJ 2011;342:c7167. [CrossRef]

3. Hakim A, Grahame R. Joint hypermobility. Best Pract Res Clin Rheumatol 2003;17:989-1004. [CrossRef]

4. Simpson MR. Benign joint hypermobility syndrome: evaluation, diagnosis, and management. J Am Osteopath Assoc 2006;106:531-6.

5. Toprak Celenay S, Ozer Kaya D. Effects of spinal stabilization exercises in women with benign joint hypermobility syndrome: a randomized controlled trial. Rheumatol Int 2017;37:1461-8. [CrossRef]

6. Reilingh ML, Kuijpers T, Tanja-Harfterkamp AM, van der Windt DA. Course and prognosis of shoulder symptoms in general practice. Rheumatology (Oxford) 2008;47:724-30. [CrossRef]

7. Akgün $\mathrm{K}$, Birtane M, Akarirmak U. Is local subacromial corticosteroid injection beneficial in subacromial impingement syndrome? Clin Rheumatol 2004;23:496-500. [CrossRef]

8. Page P. Shoulder muscle imbalance and subacromial impingement syndrome in overhead athletes. Int J Sports Phys Ther 2011;6:51-8.

9. Cowderoy GA, Lisle DA, O'Connell PT. Overuse and impingement syndromes of the shoulder in the athlete. Magn Reson Imaging Clin $\mathrm{N}$ Am 2009;17:577-93. [CrossRef]

10. Bagheri F, Ebrahimzadeh MH, Moradi A, Bidgoli HF. Factors Associated with Pain, Disability and Quality of Life in Patients Suffering from Frozen Shoulder. Arch Bone Jt Surg 2016;4:243-7.

11. Nagata H, Thomas WJ, Woods DA. The management of secondary frozen shoulder after anterior shoulder dislocation - The results of manipulation under anaesthesia and injection. J Orthop 2015;13:100-5.

12. Tamai K, Akutsu M, Yano Y. Primary frozen shoulder: brief review of pathology and imaging abnormalities. J Orthop Sci 2014;19:1-5.

13. Uppal HS, Evans JP, Smith C. Frozen shoulder: A systematic review of therapeutic options. World J Orthop 2015;6:263-8. [CrossRef]

14. Bunker TD, Reilly J, Baird KS, Hamblen DL. Expression of growth factors, cytokines and matrix metalloproteinases in frozen shoulder. J Bone Joint Surg Br 2000;82:768-73. [CrossRef]

15. Caliș M, Akgün K, Birtane M, Karacan I, Caliș H, Tüzün F. Diagnostic values of clinical diagnostic tests in subacromial impingement syndrome. Ann Rheum Dis 2000;59:44-7. [CrossRef]

16. Cadogan A, McNair PJ, Laslett M, Hing WA. Diagnostic Accuracy of Clinical Examination and Imaging Findings for Identifying Subacromial Pain. PLoS One 2016;11:e0167738. [CrossRef]

17. Bulgen DY, Binder AI, Hazleman BL, Dutton J, Roberts S. Frozen shoulder: prospective clinical study with an evaluation of three treatment regimens. Ann Rheum Dis 1984;43:353-60. [CrossRef]

18. Robinson PM, Norris J, Roberts CP. Randomized controlled trial of su- 
pervised physiotherapy versus a home exercise program after hydrodilatation for the management of primary frozen shoulder. J Shoulder Elbow Surg 2017;26:757-65. [CrossRef]

19. Grahame R, Bird HA, Child A. The revised (Brighton 1998) criteria for the diagnosis of benign joint hypermobility syndrome (BJHS). J Rheumatol 2000;27:1777-9.

20. Grahame R. Joint Hypermobility Syndrome Pain. Current Pain and Headache Reports 2009;13:427-33. [CrossRef]

21. Baeza-Velasco C, Gély-Nargeot MC, Pailhez G, Vilarrasa AB. Joint hypermobility and sport: a review of advantages and disadvantages. Curr Sports Med Rep 2013;12:291-5. [CrossRef]

22. Aktas I, Ofluoglu D, Albay T. The relationship between benign joint hypermobility syndrome and carpal tunnel syndrome. Clin Rheumatol 2008;27:1283-7. [CrossRef]

23. Aktaş İ, Ofluoğlu D, Akgün K. Relationship Between Lumbar Disc Herniation and Benign Joint Hypermobility Syndrome. Turk J Phys Med Rehab 2011;57:85-8.

24. Ofluoglu D, Gunduz OH, Kul-Panza E, Guven Z. Hypermobility in women with fibromyalgia syndrome. Clin Rheumatol 2006;25:291-3.

25. Sendur OF, Gurer G, Bozbas GT. The frequency of hypermobility and its relationship with clinical findings of fibromyalgia patients. Clin
Rheumatol 2007;26:485-7. [CrossRef]

26. Gürer G, Bozbas GT, Tuncer T, Unubol AI, Ucar UG, Memetoglu OI. Frequency of joint hypermobility in Turkish patients with knee osteoarthritis: a cross sectional multicenter study. Int J Rheum Dis 2016 Jul 27 [Epub ahead of print], doi: 10.1111/1756-185X.12883.

27. Konopinski MD, Jones GJ, Johnson MI. The effect of hypermobility on the incidence of injuries in elite-level professional soccer players: a cohort study. Am J Sports Med 2012;40:763-9. [CrossRef]

28. Tobias JH, Deere K, Palmer S, Clark EM, Clinch J. Joint hypermobility is a risk factor for musculoskeletal pain during adolescence: findings of a prospective cohort study. Arthritis Rheum 2013;65:1107-15. [CrossRef]

29. Johannessen EC, Reiten HS, Løvaas H, Maeland S, Juul-Kristensen B. Shoulder function, pain and health related quality of life in adults with joint hypermobility syndrome/Ehlers-Danlos syndrome-hypermobility type. Disabil Rehabil 2016;38:1382-90. [CrossRef]

30. Cameron KL, Duffey ML, DeBerardino TM, Stoneman PD, Jones CJ, Owens BD. Association of generalized joint hypermobility with a history of glenohumeral joint instability. J Athl Train 2010;45:253-8.

31. Terzi Y, Akgün K, Aktaş İ, Palamar D, Can G. The Relationship Between Generalized Joint Hypermobility and Adhesive Capsulitis of the Shoulder. Turk J Rheumatol 2013;28:234-41. [CrossRef] 